Pontifícia U Universidade Catálica $_{\text {a }}$

GRAVB.

Eduardo Estrella de Souza

Processo de Localização de Plataformas de Petróleo

Dissertação de Mestrado

Dissertação apresentada como requisito parcial para obtenção do título de Mestre pelo Programa de PósGraduação em Engenharia de Produção do Departamento de Engenharia Industrial da PUC-Rio.

Orientador: Prof. Nélio Domingues Pizzolato 


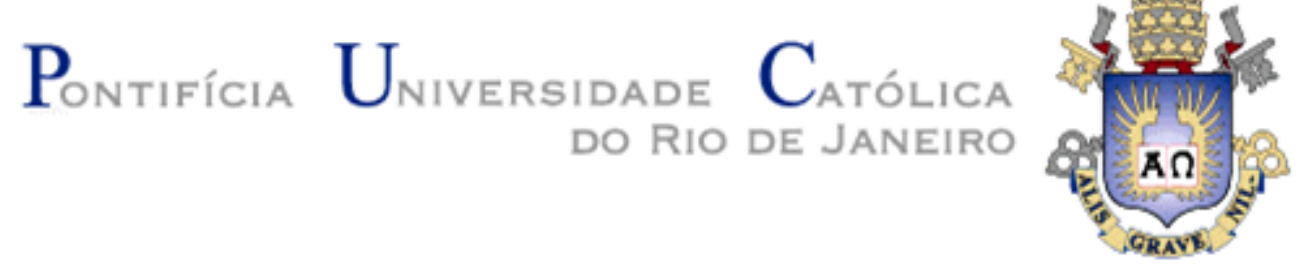

Eduardo Estrella de Souza

\title{
Processo de Localização de Plataformas de Petróleo
}

Dissertação apresentada como requisito parcial para obtenção do título de Mestre (opção profissional) pelo Programa de Pós-Graduação em Engenharia de Produção do Departamento de Engenharia Industrial da PUC-Rio. Aprovada pela Comissão Examinadora abaixo assinada.

\author{
Prof. Nélio Domingues Pizzolato \\ Presidente \\ Departamento de Engenharia Industrial - PUC-Rio
}

Prof. Adilson Elias Xavier

UFRJ

Prof. Armando Celestino Gonçalves Neto

UFRJ

Prof. Dr. José Eugênio Leal Coordenador Setorial do Centro Técnico Científico - PUC-Rio

Rio de Janeiro, 25 de abril de 2011. 
Todos os direitos reservados. É proibida a reprodução total ou parcial do trabalho sem autorização da universidade, do autor e do orientador.

\section{Eduardo Estrella de Souza}

Graduou-se em Engenharia Mecânica pela Universidade Federal Fluminense (UFF) em 1994. Especializou-se em Garantia da Qualidade no ano de 1997 pelo Instituto Militar de Engenharia (IME). Trabalha na área de Logística e Suprimentos em projetos de instalação de equipamentos submarinos e lançamento de linhas flexíveis. Dentre as principais atividades desenvolvidas estão a liberação de embarcações junto às principais autoridades brasileiras, o gerenciamento de processos de compra e importação/exportação de materiais e equipamentos, gestão de contratos de fornecimento e serviços e o gerenciamento de processos de logística e armazenagem.

Ficha Catalográfica

Souza, Eduardo Estrella de

Processo de localização de plataformas de petróleo / Eduardo Estrella de Souza ; orientador: Nélio Domingues Pizzolato. - 2011.

68 f. : il. (color.) ; $30 \mathrm{~cm}$

Dissertação (mestrado)-Pontifícia Universidade Católica do Rio de Janeiro, Departamento de Engenharia Industrial, 2011.

Inclui bibliografia

1. Engenharia Industrial - Teses. 2. Sistemas marítimos de produção. 3. Plataforma. 4. Petróleo. 5. Logística. 6. Localização. 7. Valor presente líquido. I. Pizzolato, Nélio Domingues. II. Pontifícia Universidade Católica do Rio de Janeiro. Departamento de Engenharia Industrial. III. Título. 
Dedico este trabalho aos meus pais Arthur e Nancy que sempre se empenharam em me dar a melhor educação possível, transmitindo em todos os momentos a importância de se ter uma base sólida de conhecimentos. 


\section{Agradecimentos}

Agradeço em primeiro lugar ao meu filho Rafael, que mesmo não sabendo, em função da pouca idade, me deu forças para seguir em frente.

Meu sincero agradecimento à minha companheira Fabiana, mais do que esposa $\mathrm{e}$ mulher, pela compreensão nas horas de estudo e ausência.

Agradeço também às pessoas que colaboraram com este trabalho, em especial o professor Nélio na orientação e o Vinicius Rosa fornecendo dicas importantes.

E à Deus por ter me dado esta oportunidade. 


\section{Resumo}

Souza, Eduardo Estrella de; Pizzolato, Nélio Domingues. Processo de localização de plataformas de petróleo. Rio de Janeiro, 2011. 68p. Dissertação de Mestrado (Opção profissional) - Departamento de Engenharia Industrial, Pontifícia Universidade Católica do Rio de Janeiro.

Este trabalho descreve uma sistemática para localização de plataformas de petróleo baseado em um algoritmo de localização. Como critério principal será considerada a maximização do valor presente líquido das receitas do projeto. Devido ao elevado grau de incerteza na determinação da vazão inicial de cada poço e arbitrando-se valores de vazão para cada um dos poços de produção envolvidos, será adotado um percentual que vai estabelecer níveis mínimos e máximos de vazão, procurando corrigir possíveis erros relativos ao processo inicial de coleta e interpretação de dados. Além disso, um fator randômico será introduzido no cálculo da vazão inicial com o objetivo de aumentar a confiabilidade na determinação da possível localização da plataforma. A partir destas vazões iniciais e também das vazões ao longo do tempo de vida estabelecido para os poços, será calculado o valor presente líquido das receitas de cada poço e consequentemente o percentual de participação destes poços na proximidade com a plataforma. Este percentual representa o peso de cada poço na determinação da localização final da plataforma de petróleo. Por hipótese, a superfície do fundo do mar é semelhante a um plano, portanto não são considerados obstáculos nas ligações entre os vários poços e a plataforma. Para testar a sistemática, um problema exemplo será solucionado.

\section{Palavras-chave}

Sistemas marítimos de produção; plataforma; petróleo; logística; localização; valor presente líquido. 


\section{Abstract}

Souza, Eduardo Estrella de; Pizzolato, Nélio Domingues. (Advisor) Location Proposal for Petroleum Platforms. Rio de Janeiro. 2011. 68p. MSc. Dissertation - Departamento de Engenharia Industrial, Pontifícia Universidade Católica do Rio de Janeiro.

This paper describes a system for locating oil rigs based on a general location algorithm. The problem consists in maximizing the net present revenue value of the project arbitrating discharge values for each of the production wells involved. Due to the high degree of uncertainty in determining the initial flow rate of each well it is assumed a percentage that will establish minimum and maximum levels of flow, trying to correct possible errors related to the initial collection and interpretation of data. In addition, a random factor is introduced when calculating the initial flow in order to increase reliability in determining the possible location of the platform. From these initial flow rates and also the flow over the lifetime established for the wells, the net present revenue value of each well and consequently the percentage of participation of these wells in proximity to the platform will be calculated. This percentage represents the weight of each well in determining the final location of the oil platform. The surface of the seabed is assumed similar to a plan, so no barriers are considered on the links between the various wells and the platform. A sample problem is solved to test the system described.

\section{Keywords}

Production maritime systems; platform; petroleum; logistics; location; net present value. 


\section{Sumário}

1. Introdução 12

1.1. Apresentação do Estudo 12

1.2. Objetivos 13

1.3. Estrutura da Dissertação 14

2. Instalações de Produção no Mar 15

2.1. Introdução $\quad 15$

2.1.1. Poços de Petróleo 15

2.1.2. Reservas de Petróleo 18

2.2. Unidades Estacionárias de Produção (UEP) 19

2.2.1. Classificação das UEPs 19

2.2.1.1. Jaqueta 21

2.2.1.2. Semi-Submersíveis $\quad 21$

2.2.1.3. Unidade Estacionária de Produção, Armazenagem e Transferência (FPSO) 22

2.2.1.4. Unidade Estacionária de Armazenagem e
Transferência (FSU)

3. Revisão Bibliográfica $\quad 24$

4. Contexto Teórico 29

4.1 Logística $\quad 29$

4.2 Custos na Exploração e Produção de Petróleo 32

4.2.1 Custos de Desenvolvimento 33

4.2.2 Custos de Produção 34

4.3. Receita na Produção de Petróleo 34

4.4. A Produção de Petróleo 34

4.5. Problemas de Localização de Facilidades 37

4.5.1. Tipologia dos Problemas de Localização 41

4.5.1.1. Localização em um Plano 41

4.5.1.2. Localização em uma Rede $\quad 44$

4.5.1.2.1. O Problema da p-Mediana 46

4.5.1.2.2. Os Métodos Heurísticos 48

4.5.1.2.3. Os Métodos Exatos $\quad 49$

4.6. Outros Problemas Fundamentais de Localização 49

4.6.1. O Problema da Localização com Cobertura Completa 49

4.6.2. O Problema da Localização com Cobertura Máxima 50

5. Modelagem do Problema 51

5.1. Introdução 51

5.2. Representação da Superfície do Mar em um Plano 52

5.3. Determinação das Coordenadas dos Poços 52

5.4. Cálculo das Vazões de Óleo ao Longo do Tempo 52

5.5. Cálculo do VPLR Associado a Cada Posição da UEP 54

5.6. Problema Exemplo 56 
6. Conclusões

59

6.1. Avaliação dos Resultados

59

6.2. Propostas para Trabalhos Futuros

Referências Bibliográficas

66 


\section{Lista de figuras}

Figura 1: Disposição de poços no leito submarino e conexões flexíveis

Figura 2: Plataforma tipo Jaqueta 21

Figura 3: Plataforma Semi-submersível 22

Figura 4: Unidade de Produção, Armazenagem e Transferência (FPSO)

Figura 5: Localização dos poços

Figura 6: Curva de Valor Presente Líquido das Receitas para cada poço

Figura 7: Localização da plataforma e poços 


\section{Lista de quadros}

Quadro 1: Metodologia proposta para localizar UEPs 55

Quadro 2: Relação de coeficientes "a" e "b" e Qo 57

Quadro 3: Faixa de valores mínimos e máximos de vazão incerteza de $5 \%$

Quadro 4: Parâmetros da Receita 58

Quadro 5: Percentuais de participação de cada poço 61

Quadro 6: Valores totais de VPLR para cada poço 62 